\title{
Improving Communication Between Health Care Professionals and Parents: A Quality Improvement Initiative
}

\author{
POONAM JOSHI ${ }^{1, *}$, MEENA JOSHI ${ }^{2}$, AAKANSHA SHARMA ${ }^{2}$, ANU \\ SACHDEVA $^{2}$, RAJESH SAGAR ${ }^{3}$ AND ASHOK KUMAR DEORARI ${ }^{2}$ \\ ${ }^{1}$ College of Nursing, All India Institute of Medical Sciences, New Delhi. \\ ${ }^{2}$ Department of Pediatrics, All India Institute of Medical Sciences, New Delhi. \\ ${ }^{3}$ Department of Psychiatry, All India Institute of Medical Sciences, New Delhi. \\ *Email: pjoshi495@ gmail.com
}

Received: July 23, 2017| Revised: August 18, 2017| Accepted: August 29, 2017

Published online: October 02, 2017

The Author(s) 2017. This article is published with open access at www.chitkara.edu.in/Publications

\begin{abstract}
This quality improvement initiative was undertaken in a tertiary care neonatal intensive care unit (NICU) to improve communication between the HCP and parents related to the sick neonates admitted in NICU as measured by increase in parental satisfaction score from base line $(34.5 \%)$ to $80 \%$ in 3 months time. A team was formulated to evaluate the reasons for low parental satisfaction resulting from communication between HCP and the parents of sick neonates and to further plan strategies for improving the same. Multiple PDSA cycles were implemented. The results of the all PDSA cycles were discussed amongst team members. Satisfaction of parents related to communication with HCP increased to more than $80 \%$ in 3 months time followed by increase up to $90 \%$ in sustenance phase. Multiple simple feasible interventions led to improvement in communication between the HCP and parents as evident by increase in satisfaction score $(40.8 \pm 4.3$ vs. $40.8 \pm 4.3$ vs. $91.3 \pm 4.8$, p $<0.001)$.
\end{abstract}

There was significant improvement in the satisfaction scores of the mothers on communication related to sick neonate in NICU at the end of intervention phase as well as in the sustenance phase. Multiple simple doable and feasible interventions had led to the improvement in communication between the $\mathrm{HCP}$ and parents hence improving the satisfaction of parents related to their communication with HCP.

Keywords: Communication, Satisfaction, Neonatal Intensive Care Unit (NICU) and Quality improvement (QI)
Journal of Multidisciplinary Research in Healthcare Vol-4, No-1, October 2017 pp. 1-9


Joshi, P

Joshi, M

Sharma, A

Sachdeva, A

Sagar, R

Deorari, AK

\section{INTRODUCTION}

Hospitalization of a sick neonate in a neonatal intensive care unit (NICU) is a source of stress for their parents. Complex physical and technical environment of NICU further adds to their stress and necessitates for their proper ongoing counselling and support.[1] In NICU, patient is the newborn and the recipient of information is the parent. Counselling of the parents of sick neonates is to be highly individualized and tailored according the needs of the parents depending upon their educational background, cultural differences, beliefs and the clinical condition of the sick neonate.[2]

Admission of neonate in NICU is a significant stress for the parents especially the mothers as they themselves are recovering from the process of child birth.[3] The major concerns of mothers during this stressful time are their informational needs, grief response, their relationship development with the neonate, stress, and coping and social support.[4] In most hospitals in India and world over, still traditional NICU care is being provided to the sick neonates without involving mothers in baby care. The parents are only allowed to see the neonate once a day and updated about her condition. The existing system does not allow active participation of mothers in newborn care. [5] Higher parental satisfaction and lower stress levels are considered to be the major determinants in the prompt recovery of the neonate as well the postpartum mother.[6-7] Studies have identified 11 dimensions of care as important to parents whose infants receive neonatal intensive care: assurance, caring, communication, consistent information, education, environment, follow-up care, pain management, participation, proximity, and support.[8]

Communication is an important aspect of patient care in any intensive care unit (ICU) and neonatal intensive care unit (NICU) is no exception. Proper informative communication between the HCP and the parents can help in reducing the parental stress occurring due to the hospitalization of their sick neonate. Further, planned informative communication between the health care professionals (HCP) and parents makes them aware of the newborn's condition, empowers them with knowledge and helps them in decision making. [2] This in turn acts as the building block for parents in developing trusting relationship with the HCP. There are some studies [9-10] that suggest that HCP in general and nurses in specific are the primary source of information. The HCP are generally less easily accessible to the parents of newborn due to their busy schedule, but parents are satisfied, whenever they get opportunity to talk to them. [10]

Good communication skills are required for nurturing parents' satisfaction. In our unit, high standard quality care is provided to the admitted sick neonates, but we observed that there were no planned informative communication 
sessions held between the HCP and the parents; only casual interactions were seen, resulting in low satisfaction among the parents. In view of this identified problem, we decided to initiate a quality improvement project to improve communication between health care professionals (HCP) and the parents of admitted sick neonates. Outcome measure was the improvement in parental satisfaction with the communication with the HCP. So that we could help the parents to understand the clinical condition of the child and cope with it successfully.

\section{MATERIAL AND METHODS}

This quality improvement initiative was conducted in a level-3 NICU of a tertiary care hospital from February to April 2017 to improve the communication between the HCP and the parents. Parents were mainly the mothers, whose sick neonates were admitted for more than 3 days in NICU. We have two NICUs (NICU A \&B) in our hospital. In NICU A, very sick critically sick babies are admitted and after stabilization are shifted to NICU B. Both NICUs are having similar facilities.

A QI team consisting of a nurse educator, a resident and nurses of both NICU (2 each) and NICU faculty in-charge was formulated. As it was a quality improvement initiative, no ethical clearance was required from the institute. Confidentiality and anonymity of subjects was ensured during the study.

Baseline data collection was done from 5 mothers using a pre-validated semi-structured communication satisfaction tool, followed by two focus group discussions (FGD) with the group of mothers and HCP separately, that helped us to reach to the root causes of the problem. The FGD for both the groups started with an interview guide consisting of few trigger questions to find out the reasons for poor communication between the HCP and parents. The trigger questions in FGD for mothers were related to the condition of the baby, duration of stay, explanation given to them by $\mathrm{HCP}$ about the neonate and their expectations from the HCP and satisfaction with the information received etc. The FGD for HCP included the trigger questions related to "why the communication on the part of HCP was lacking".

The communication satisfaction tool had five items enquiring about their satisfaction in relation to the conversation they had with HCP, being treated caringly and respectfully without any hurry in NICU, receiving daily information about their baby from the HCP, their involvement in baby care, and decision making related to sick neonate measured on five point Likert scale - highly satisfied (5), satisfied (4), cannot say (3), dissatisfied (2) and highly dissatisfied (1). The other 3 items included were "How easy was it to
Improving Communication

Between Health Care Professionals and Parents:

A Quality Improvement Initiative 
Joshi, P

Joshi, M

Sharma, A

Sachdeva, A

Sagar, R

Deorari, AK

communicate with HCP? Did they receive answers to all their questions? How easy it was for them to understand the information received by HCP. The total satisfaction score of the parents ranged from $0-40$. There were two open ended questions, "Did they feel something missing the communication; and would they like to give some suggestions to improve communication between $\mathrm{HCP}$ and parents? The same were analysed quantitatively by categorizing the responses

Baseline data collection revealed that all mothers knew reasons for their babies' admission in NICU and expressed that some issues related to babies' condition were addressed and they occasionally received information about their sick neonates and wanted more information. Suggestions given by mothers to improve communication were multiple; a) HCP should give more information in an organized manner, taking adequate time $(16.7 \%)$, b) should be polite and respectful to the emotions of the mothers $(66.4 \%)$, c) they should not talk on mobile phone while caring the sick babies $(16.7 \%)$.

In focus group discussion (FDG) HCP had expressed number of reasons like busy schedule, work load, prolonged rounds, long duty hours of neonatologists, language problem, no perceived need for holding informative communication with parents and considering someone might have already explained the parents about clinical condition of the sick neonate etc., which created hindrance to effective communication. Prior to this QI project, there was no policy in unit as such to formally communicate with parents. Discussion with the group of mothers revealed some more reasons like hesitant mothers, lack of privacy as no separate room for talking to HCP, and insensitive HCP for poor communication between HCP and parents (figure1).

\section{ROOT CAUSE ANALYSIS}

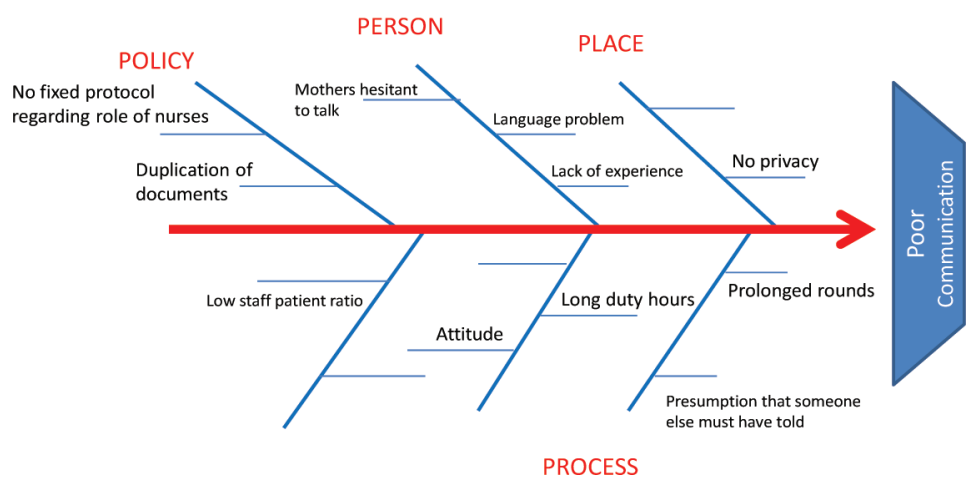

Figure 1: Root cause analysis. 


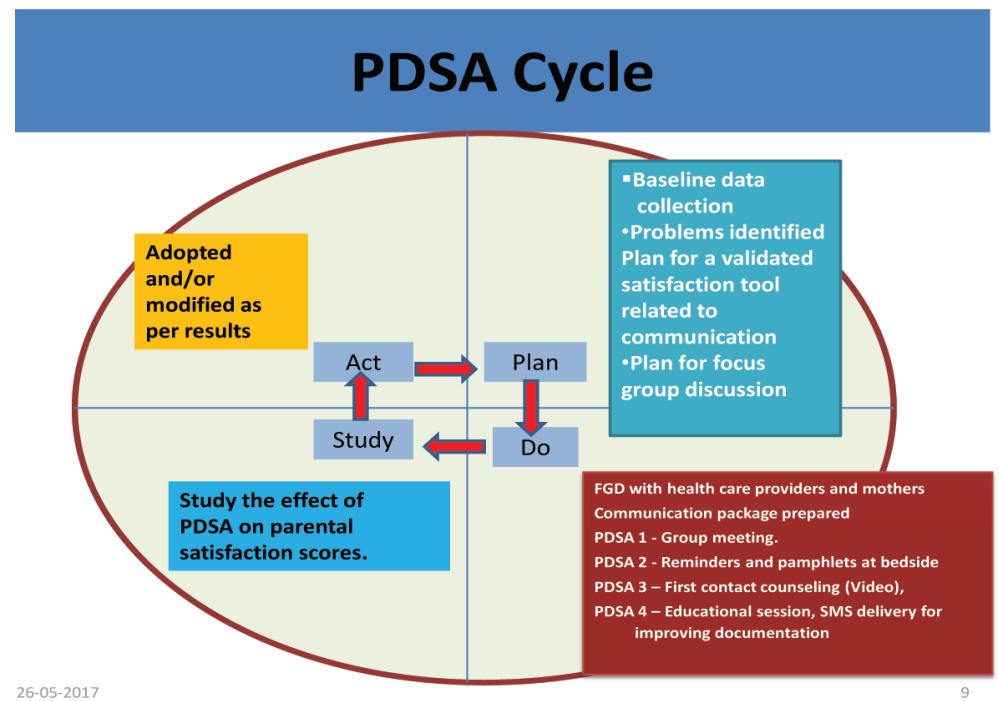

Improving

Communication

Between Health

Care Professionals

and Parents:

A Quality

Improvement

Initiative

Figure 2: PDSA cycles.

\section{INTERVENTION}

After problem analysis, four change ideas were introduced, one after another as an add-on strategy, and tested as part of Plan- Do - Study - Act (PDSA) cycles (Figure 2). In first PDSA cycle group meeting was held with the HCP to sensitize them about the importance of communication. In second PDSA cycle, reminders at the bed side in the form of pamphlets were displayed. Pamphlet included reminder for communication and barriers to communication like no communication, wrong communication, miscommunication, communication to wrong person, inappropriate body language, lack of active listening, no empathy, rude/ disrespect attitude, lack of adequate knowledge etc.

Our PDSA cycle 2 did not show much improvement in satisfaction score. The probable reason for the failure of pamphlet to leave any impact on parents' satisfaction score was the inability of HCP to understand the barriers of communication listed in the pamphlet and wanted more explanation. In PDSA cycle 3 along with reminders, HCP were familiarized with first contact counseling using a video developed by the nurse educator, further all primary nurses were made accountable to provide first counseling to the parents along with information about the clinical condition of the sick neonate within 24 hours of their babies admission in NICU. Documentation of first contact and ongoing counselling was made mandatory and the quality of the counselling was evaluated using a structured first contact counselling checklist. Finally in PDSA cycle 4, an educational session on importance of communication and formal counseling 
Joshi, P

Joshi, M

Sharma, A

Sachdeva, A

Sagar, R

Deorari, AK and how to counsel the parents of sick neonates was arranged by an expert. In addition, as part of reinforcement, daily SMS reminders on documentation of both first contact and ongoing counselling were delivered by the nurse educator.

The collected data was coded, entered in excel sheet and analyzed using SPSS 23.00. Parents' satisfaction scores before and after the PDSA cycles were analyzed using independent't' test. A 'p' value of $<0.05$ was considered as significant.

\section{RESULTS}

Results of all PDSA cycles were discussed by nurse educator with the QI team members as part of feedback. The results obtained were very encouraging. One of the balancing outcome, we observed was the development of initial conflict between the parents and HCP, which got resolved, as we made progress in our QI project.

The mean satisfaction score of the parents related to communication with $\mathrm{HCP}$ at baseline was $40.8 \pm 4.3\left(\mathrm{n}_{1}=5\right)$ that increased to $80.8 \pm 4.5$ at the end of the intervention phase (over three months time) (40.8 $\pm 4.3 \mathrm{vs}$. $80.8 \pm 4.5, \mathrm{p}<0.05)$ and continued to show sustained results $(91.3 \pm 4.8)$ one month following the completion of the QI project (Table 1).

Table 1: Satisfaction scores of mothers on communication related to sick neonate in NICU.

\begin{tabular}{|c|c|c|c|c|c|}
\hline Scores & $\begin{array}{l}\text { Baseline } \\
\mathbf{n}_{1}=\mathbf{5}\end{array}$ & $\begin{array}{l}\text { At the end of } \\
\text { intervention } \\
\left(\mathbf{n}_{2}=7\right)\end{array}$ & $\begin{array}{l}\text { Sustenance } \\
\text { phase } \\
\left(\mathbf{n}_{3}=7\right)\end{array}$ & p value & $\begin{array}{l}\text { Interventions } \\
\text { (PDSA cycles) }\end{array}$ \\
\hline Satisfaction & $40.8 \pm 4.3$ & $80.8 \pm 4.5$ & $91.3 \pm 4.8$ & $0.001 *$ & $\begin{array}{l}\text { - Meeting with HCP } \\
\text { - Pamphlet display } \\
\text { as reminders } \\
\text { - First contact } \\
\text { counselling using } \\
\text { video } \\
\text { - Educational } \\
\text { session on } \\
\text { communication by } \\
\text { expert and daily } \\
\text { SMS reminders } \\
\text { for first contact } \\
\text { and ongoing } \\
\text { counselling }\end{array}$ \\
\hline
\end{tabular}




\section{DISCUSSION}

Major finding of our study revealed significant improvement in the parents' satisfaction score related to communication with HCP on their sick neonates. More parents in post intervention phase were daily updated by the HCP and felt involved in decision making process as compared to pre-intervention phase.

The present study suggests that multiple simple feasible interventions on improving communication between the parents and HCP like sensitizing HCP with informative communication and counselling, introducing first contact and ongoing counselling with its documentation and an educational session by an expert led to the improvement in the satisfaction scores of the parents. Our study results are in line with the results presented by Margot Van de V et al. [11] Reis et al. [12], Batra P etal.[13] in which an improvement was observed in parents' satisfaction with communication from neonatal staff following the implementation of individual baby diaries. Present study has no limitations as such. Quality improvement project is different from standard research work as it is highly contextual, ongoing and the improvement is observed in terms of bringing change in the existing system. With the help of this QI initiative the researcher along with her working team has tried to bring about change in the system. It would be prudent to monitor the change in the system on long term basis. The results of QI projects were evident immediately, hence encouraged the health care to team to further improve the system.

This is a single centre QI project that helped in sensitizing the HCP about the importance of planned informative communication. We have learnt few lessons from the present QI project. The first lesson learnt is on the importance of having team dynamics and the commitment of the team members for the success of a QI project. Staff sensitization with frequent QI meetings and educational session brought a positive change in communication between the parents and HCP. The second learning was in relation to adapting the change with some modification. Our second PDSA cycle in which reminders were displayed at the bedside was not very successful, but it worked well in combination with other strategies like mandatory first contact counselling within 24 hours of admission of neonate to NICU, followed by ongoing counselling and its documentation. We could successfully complete our QI project without requiring any financial support from outside. The change ideas that we introduced, now have become part of our system as evident by sustained satisfaction scores of parents (more than $90 \%$ ).

\section{CONCLUSION}

There was significant improvement in the satisfaction scores of the mothers on communication related to sick neonate in NICU at the end of intervention
Improving

Communication

Between Health

Care Professionals and Parents:

A Quality

Improvement

Initiative 
Joshi, P

Joshi, M

Sharma, A

Sachdeva, A

Sagar, R

Deorari, AK phase as well as in the sustenance phase. Multiple simple doable and feasible interventions had led to the improvement in communication between the $\mathrm{HCP}$ and parents hence improving the satisfaction of parents related to their communication with HCP.

\section{Compliance with ethical standards \\ Conflict of interest - None \\ Source of Funding - None}

\section{REFERENCES}

[1] Alderson P, Hawthorne J, Killen M. Parents' experiences of sharing neonatal information and decisions: Consent, cost and risk. Soc Sci Med. 2006; 62: 1319-29.

[2] Yee W, Ross S. Communicating with parents of high-risk infants in neonatal intensive care. Paediatr Child Health. 2006 May; 11(5): 291-294.

[3] Institute of Medicine (US) Committee on Understanding Premature Birth and Assuring Healthy Outcomes. Behrman RE, Butler AS, eds. Preterm birth: Causes, consequences, and prevention. Washington: National Academies Press (US), 2007. http://dx .doi.org/10.17226/11622.

[4] Fishering R, Broeder JL, Donze A. A qualitative study: NICU nurses as NICU parents. Adv Neonatal Care 2016;16(1):74-86. http://dx.doi. org/110.1097/anc.00000000000002213.

[5] Chourasia N, Surianarayanan P, Adhisivam B, Vishnu Bhat B. NICU admissions and maternal stress levels. Indian J Pediatr 2013;80(5):380-384. http://dx.doi.org/10.1007/s12098-012-0921-7 4.

[6] Bastani F, Abadi TA, Haghani H. Effect of family-centred care on improving parental satisfaction and reducing readmission among premature infants: A randomized controlled trial. J Clin Diagn Res 2015;9(1):SC04-8. http://dx.doi. org/10.7860/jcdr/2015/10356.5444 5.

[7] Blackington SM, Mclauchlan T. Continuous quality improvement in the neonatal intensive care unit: Evaluating parent satisfaction. J Nurs Care Qual 1995;9(4):78-85. http://dx.doi. org/10.1097/00001786-199507000-0001.

[8] Ranchod T, Ballot DE, Martinez AM, Cory BJ, Davies VA, Partridge JC. Parental perception of neonatal intensive care in public sector hospitals in South Africa. S Afr Med J 2004;94(11):913-916.

[9] Kowalski WJ, Leef KH, Mackley A, Spear ML, Paul DA. Communicating with parents of premature infants: Who is the informant? J Perinatol. 2006; 26:44-8.

[10] Abel-Boone H, Dokecki PR, Smith MS. Parent and health care provider communication and decision making in the intensive care nursery. Child Health Care. 1989;18:133-41.

[11] Vijver van de Margret, Evans M. A tool to improve communication in the neonatal unit. BMJ Qual Improv Report 2015;4: doi:10.1136/bmjquality.u203180.w3084. [accessed on June 16, 2017]. 
[12] Reis MD, Scott SD, Rempel GR. Including parents in the evaluation of clinical microsystems in the neonatal intensive care unit. Adv Neonatal Care 2009; 9:174-179. http://dx.doi.org/110.1097/anc.0b013e3181afab3c.(accessed on July 20, 2017)

[13] V Sankar, P Batra, M Saroha, J Sadiza. Parental satisfaction in the traditional system of neonatal intensive care unit services in a public sector hospital in North India. SAJCH 2017; 11(1): 54-57.

Improving Communication Between Health Care Professionals and Parents: A Quality Improvement Initiative 